\title{
Influence of different types of reinforcements on the embedment behavior of steel dowels in wood
}

\author{
Wolfgang Lederer $^{1} \cdot$ Thomas K. Bader $^{1} \cdot$ Gerhard Unger $^{1} \cdot$ Josef Eberhardsteiner $^{1}$
}

Received: 21 May 2015/Published online: 9 June 2016

(C) The Author(s) 2016. This article is published with open access at Springerlink.com

\begin{abstract}
In this study, dowel displacement-embedment stress relationships for different types, numbers and positions of reinforcements were experimentally investigated using a half-hole embedment test setup. Tests were performed parallel to the grain and in compression. Screws with a full or partial thread at different positions below the dowel and oriented strand board, plywood and nail plates on the loaded surfaces of the specimens, served as reinforcements. Test results underline their potential for an increased ductility of dowel-type connections. Comparison of reinforced and unreinforced specimens suggests premature failure of the unreinforced wood and consequently, an underestimation of the embedment strength as it is subsequently used in the design of dowel connections using the European yield model. This was supported by the investigation of cracks on the surface of the specimens visualized by means of a full-field deformation measurement system. It could be demonstrated that the strength in the embedment test even further increases if the reinforcement elements actively contribute to the load transfer. This property however cannot be considered as embedment strength, but represents the strength of a connection system. Test data is compared to the design equation in Eurocode 5.
\end{abstract}

Electronic supplementary material The online version of this article (doi:10.1007/s00107-016-1058-6) contains supplementary material, which is available to authorized users.

Wolfgang Lederer

wolfgang.lederer@tuwien.ac.at

1 Institute for Mechanics of Materials and Structures, Vienna University of Technology, Karlsplatz 13/e202, 1040 Vienna, Austria

\section{Introduction}

The embedment behavior of dowel-type fasteners in wood is an important characteristic in the design of timber connections and strongly influences their strength. For the experimental characterization of embedment properties, different test standards (EN 383 2007; ASTM D5764-97a 2013; ISO 10984-2 2009) exist, which follow the same principles but deviate in some details in the calculation of embedment properties (see e.g. Franke and Magnière 2014). Essentially, the embedment strength as the average stress under the steel dowel at the maximum load up to a specific dowel displacement, is determined and subsequently used in the strength calculation of connections. The maximum admissible displacement of a dowel is $5 \mathrm{~mm}$ according to EN 383, while ASTM D5764-97a prescribes a $5 \%$ (of the fasteners diameter)-offset method for the calculation of the embedment strength.

A particular advantage of dowel-type connections is their ductile behavior, which allows for large relative deformations and rotations between timber elements (Jorissen and Fragiacomo 2011; Brühl et al. 2011). Under such conditions, large dowel displacements are encountered. Similar to embedment testing, large displacements are only possible if splitting of the specimen along the grain direction of the wood, due to tensile stresses perpendicular to the grain, is avoided. For this purpose, testing and design standards prescribe minimum specimen dimensions and dowel spacing. However, the maximum displacement for the determination of embedment properties is $5 \mathrm{~mm}$. Alternatively, several different types of reinforcement are available and applied in practical applications to ensure a ductile behavior. In order to account for the high ductility of reinforced connections, also embedment tests should be conducted up to large displacements, 
i.e. far beyond the current limit of $5 \mathrm{~mm}$. Thus, reinforcements should also be used in embedment testing to avoid premature splitting of the test specimen.

Embedment tests on wood have been performed by many researchers and on different types of softwood and hardwood. The design equation in the European standard for the design of timber structures (EN 1995-1-1 2004) is based on experimental work by Ehlbeck and Werner (1992) and Whale and Smith (1986), as documented for example in Sandhaas et al. (2013). The latter discusses embedment characteristics over a broad range of densities and also ductility aspects as regards different wood species.

Data for the influence of reinforcements on the embedment properties measured in embedment tests is scarce and mostly limited to the above mentioned displacement limit. Strengthening solutions based on adhesively bonded reinforcement techniques were experimentally investigated in embedment tests by Santos et al. (2010). Bejtka (2005) studied dowel connections reinforced with self-tapping screws and developed analytical formulas for their design. Blass et al. (2000) investigated the potential of nail plates as reinforcement of doweltype connections and observed an increased bearing strength of such connections, since an additional load was transferred through the nail plate. Similarly, other types of high strength materials (e.g. plywood, laminated veneer lumber, etc.) were used on the side faces of the wood to reinforce the connection perpendicular to the grain (Larsen and Jensen 2000; Rodd and Leijten 2003). Since decades, these materials are widely used in practical applications not only for reinforcement of connections (Blass et al. 1988) but also for reinforcement of notches and holes (DIN EN 1995-1-1/NA 2013).

In the experimental work presented herein, the effect of different types and numbers of reinforcements on the embedment behavior of steel dowels with a diameter of $12 \mathrm{~mm}$ in wood was studied. In more detail, a half-hole test setup according to ASTM D5764-97a is applied and corresponding load-displacement characteristics of the reinforced wood specimens loaded parallel to the grain, with dowel displacements up to $30 \mathrm{~mm}$, are studied. In this way, the suitability of reinforcements for the testing of embedment properties up to large displacements will be assessed.

Results of embedment tests according to the ASTM D5764-97a were shown to be comparable to tests performed according to the European test method EN 383. The embedment strength was similar, while a difference in the stiffness was observed (Franke and Magnière 2014; Santos et al. 2010). One advantage of the ASTM test setup is the uniform load distribution, since a bending of the steel dowel is avoided. However, in general, the ASTM test setup is more prone to splitting and thus, was chosen for the investigation of the effect of reinforcements on embedment properties.

\section{Materials and methods}

In total, 10 test series with different types of reinforcements were conducted with one additional test series without reinforcement, which served as a reference. The reinforcement measures can be divided into two main groups, namely those with screws as dowel-type reinforcement and those with engineered wood products and nail plates as surface reinforcement. Additionally, embedment properties of oriented strand board (OSB) and plywood have been assessed in order to complement the experimental database.

\subsection{Wood specimens and test setup}

Preparation of wood specimens was based on the requirements for half-hole test specimen proposed by ASTM D5764-97a (2013), because this setup is particularly prone to splitting of the wood specimens. The setup is illustrated in Fig. 1 for the two different types of reinforced specimens. Tests were performed as compression tests and the load was applied displacement-controlled through a rough steel plate of steel quality S 325 and a thickness of $8 \mathrm{~mm}$. This steel plate was connected to an electrolytically galvanized dowel with a diameter of $12 \mathrm{~mm}$.

All samples were prepared of Norway spruce (Picea abies) beams that were taken from a local wood trader. Timber beams from strength classes C16, C24 and C30 (according to EN 338 2003) were selected with the aim to obtain specimens with different densities, and thus, with different mechanical properties. Cubic specimens of clear wood without growth irregularities and with dimensions of $100 \times 100 \times 100 \mathrm{~mm}^{3}$ were cut out and planed. Clear wood specimens have been used in order to avoid influences of growth irregularities on the embedment behavior (ASTM D5764-97a 2013). For drilling, two specimens were put together and a $12 \mathrm{~mm}$ hole was produced with a slot drilling machine. The center of this hole was located right in the middle of the verge of the two samples so that two half-hole specimens were obtained (Fig. 1a). For two test series, the dimensions of the specimens differed due to the type and position of reinforcement. In these two cases of screws positioned close to the dowel, the length in the grain direction of the cubic specimens was $130 \mathrm{~mm}$ (Fig. 1a). Again, the hole with a diameter of $12 \mathrm{~mm}$ was drilled with a slot drilling machine with its center at a height of $100 \mathrm{~mm}$. Subsequently, two cuts with a band saw established an open slot for the loading device (Fig. 1a). 

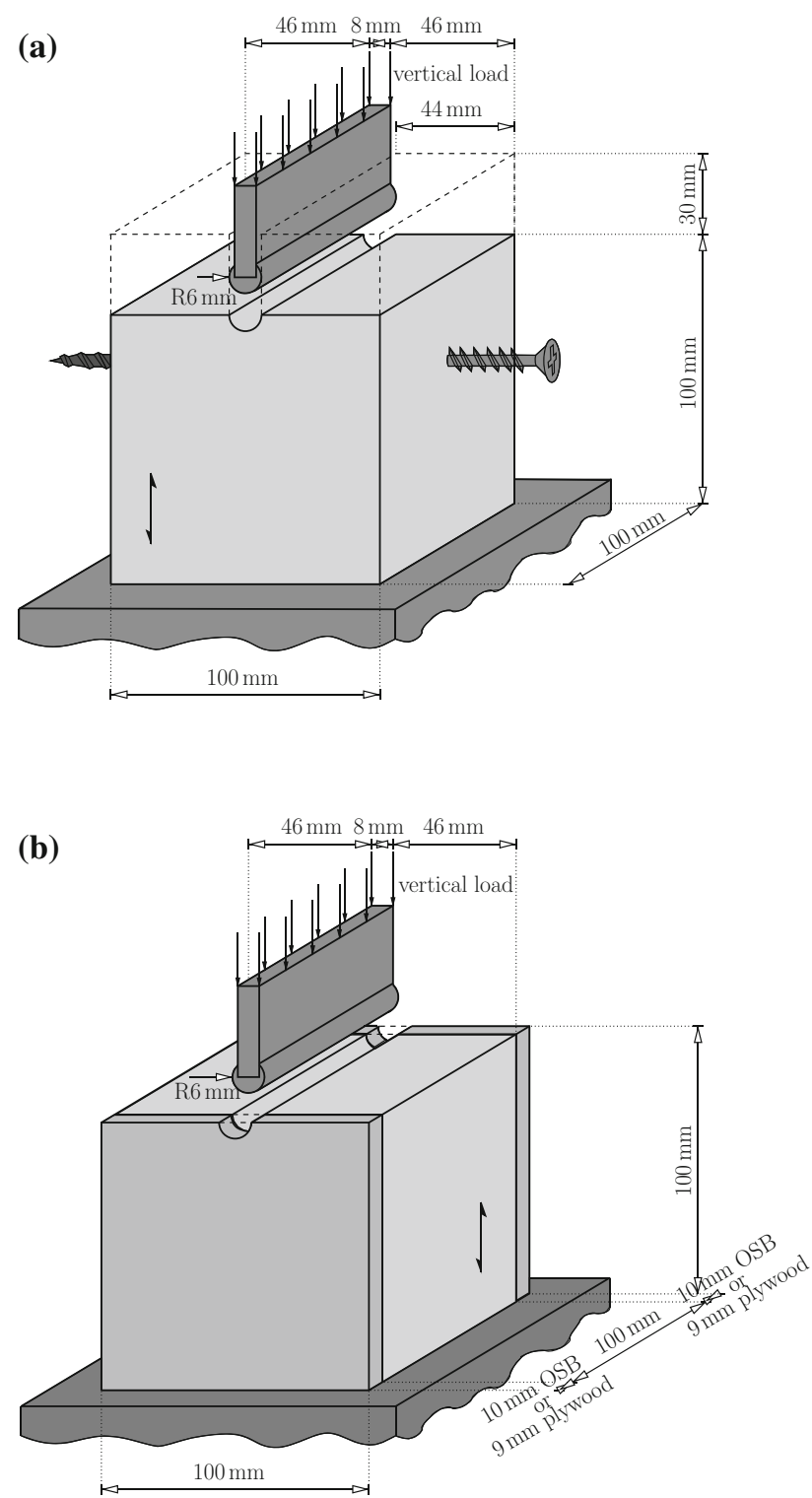

Fig. 1 Embedment test setup with a dowel-type reinforced wood specimens, b surface reinforced wood specimens

The minimum width and length of specimens according to ASTM D5764-97a (2013) are 4 times the dowel diameter or $50 \mathrm{~mm}$, while a minimum width of 6 and a minimum length of 7 times the dowel diameter would be required according to EN 383 (2007). Thus, the test specimens used herein satisfy both requirements.

The embedment behavior of OSB and plywood panels was tested as well. OSB 3 Kingspan TEK ${ }^{\odot}$ (Kingspan Insulation Ltd., UK) with a thickness of $10 \mathrm{~mm}$ and birch plywood with a thickness of $9 \mathrm{~mm}\left(W I S A^{\odot}-B I R C H\right.$, UPM Plywood, Finland) was used. For the purpose of embedment testing, five plates with dimensions of $100 \times 100 \mathrm{~mm}^{2}$ and a thickness of 10 and $9 \mathrm{~mm}$, respectively, were glued together. This resulted in test specimens with a thickness of 50 and $45 \mathrm{~mm}$ for OSB and plywood, respectively, which were tested following the same procedure as outlined below. SEMPAROC $60^{\circ}$ (Collano Adhesives AG, Switzerland) was used for all adhesive bonds. With a spreader, this glue was applied to the clean and dry surface (100 to $300 \mathrm{~g} / \mathrm{m}^{2}$ ) before the elements were pressed together for at least $4 \mathrm{~h}$.

Before testing, all specimens were stored in a climate chamber at $20{ }^{\circ} \mathrm{C}$ and $65 \%$ relative humidity, which yielded $12 \%$ wood moisture content. The corresponding wood densities at $12 \%$ wood moisture content amounted to 384 to $512 \mathrm{~kg} / \mathrm{m}^{3}$ and are specimen-specifically documented. The density of the OSB and the plywood panel amounted to 485 and $681 \mathrm{~kg} / \mathrm{m}^{3}$, respectively.

\subsection{Test series}

In the following, a description of the individual test series related to a specific type, position and number of reinforcements, is given. The test series are grouped into reference tests on unreinforced specimens, specimens with dowel-type reinforcements, and specimens with surface reinforcements. In order to be able to compute meaningful average values and standard deviations, each test series encompassed 11 replications.

(1) Unreinforced reference specimens In this test series, 11 unreinforced half-hole specimens without reinforcement were tested. Since OSB and plywood were used for surface reinforcement, additionally, their embedment behavior was investigated by means of 4 specimens each.

(2) Dowel-type reinforcements In order to ensure a high accuracy in the position of the screws, holes with a diameter of 4 and $6 \mathrm{~mm}$ for screws with a diameter of 6 and $8 \mathrm{~mm}$ were drilled with a slot drilling machine, before the screws where finally placed into the wooden specimens.

- $2 \times 6 \mathrm{~mm} 2 d$ : two screws SPAX HI.FORCE ${ }^{\odot}$ (producer: SPAX International GmbH \& Co. KG) with a diameter of $6 \mathrm{~mm}$ and with a length of 100 $\mathrm{mm}$ were placed at a distance of 2 times the dowel diameter below the center of the dowel itself. As these screws have a partial thread they were screwed into the sample mirror-inverted at the third points of the specimen width to account for a uniform and symmetric reinforcement (Fig. 2a).

- $1 \times 8 \mathrm{~mm} 2 \mathrm{~d}$ : one fully threaded screw SPAX T-STAR plus ${ }^{\odot}$ with a diameter of $8 \mathrm{~mm}$ and a length of $180 \mathrm{~mm}$ was placed in the specimens at a distance of 2 times the dowel diameter below 
Fig. 2 Test specimens with dowel-type reinforcements:

a for series $2 \times 6 \mathrm{~mm} 2 d$; $\mathbf{b}$ for series $1 \times 8 \mathrm{~mm} 2 d$; $\mathbf{c}$ for series

$2 \times 8 \mathrm{~mm} 2 d$; $\mathbf{d}$ for series

$2 \times 6 \mathrm{~mm}$ contact $; \mathbf{e}$ for series 1 $\times 8 \mathrm{~mm}$ contact (a)

TOP VIEW
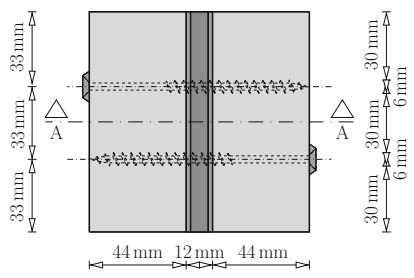

(b)

TOP VIEW
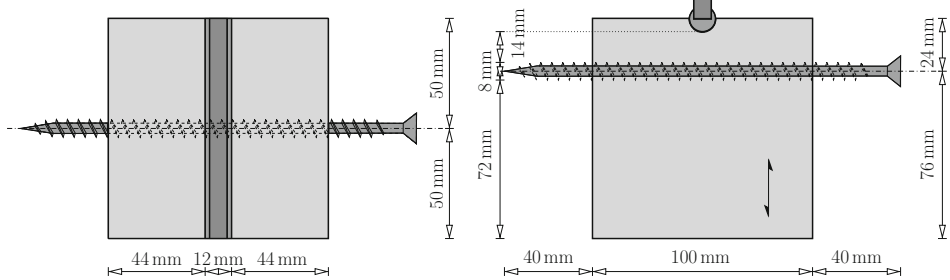

(c)

TOP VIEW

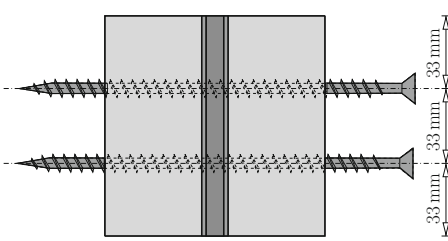

$44 \mathrm{~mm} 12 \mathrm{~mm} 44 \mathrm{~mm}$

(d)

TOP VIEW

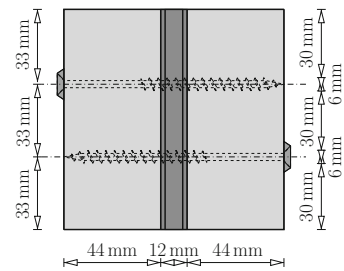

CROSS SECTION A-A

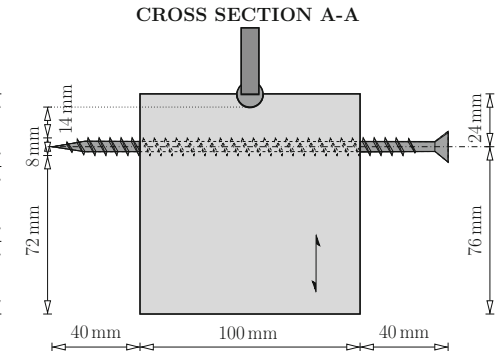

(e)

TOP VIEW
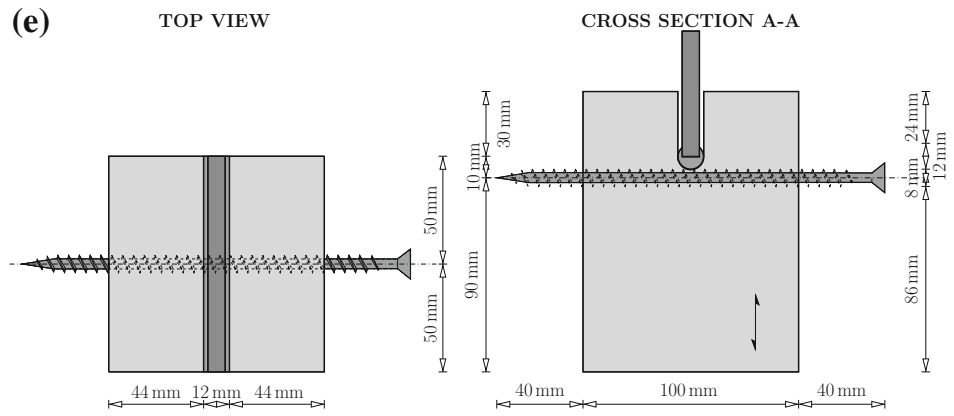
and orthogonal to the dowel itself right in the center of the sample (Fig. 2b).

$-2 \times 8 \mathrm{~mm} 2 d$ : this test series is similar to the setup of $1 \times 8 \mathrm{~mm} 2 d$ with the difference that two screws SPAX T-STAR plus ${ }^{\odot}$ with a diameter of $8 \mathrm{~mm}$ were used (Fig. 2c).

- $2 \times 6 \mathrm{~mm}$ contact: the same screws (SPAX HI.FORCE $E^{\odot}$ with a diameter of $6 \mathrm{~mm}$ ) as for test series $2 \times 6 \mathrm{~mm} 2 d$, but placed right below the dowel, were used in this series. Thus, the dowel was in initial contact with the screws right from the beginning of loading. As outlined in Section 2.1, wood specimens are $30 \mathrm{~mm}$ longer in order to prevent splitting during the insertion of the screws (Fig. 2d).

- $1 \times 8 \mathrm{~mm}$ contact: The same screw (SPAX $T$-STAR plus ${ }^{\circledR}$ with a diameter of $8 \mathrm{~mm}$ ) as for test series $1 \times 8 \mathrm{~mm} 2 d$, but placed right below the dowel, is used in this series. Thus, the dowel was in initial contact with the screw right from the beginning of loading. As outlined in Section 2.1, wood specimens are $30 \mathrm{~mm}$ longer in order to prevent splitting during the insertion of the screws (Fig. 2e).

\section{(3) Surface reinforcements:}

- $10 \mathrm{~mm}$ OSB without hole: Specimens in this test series were reinforced by $10 \mathrm{~mm}$ OSB 3 Kingspan $T E K^{\odot}$ (Kingspan Insulation Ltd., UK) plates which were glued onto each loaded side of the specimens. The OSB plates were continuous without hole and the dowel loaded the wooden part only (Fig. 3a). The thickness of the reinforced specimens was $120 \mathrm{~mm}$.

- $9 \mathrm{~mm}$ plywood without hole: Specimens in this test series were reinforced by $9 \mathrm{~mm}$ birch plywood plates $\left(W I S A^{\odot}-B I R C H\right.$, UPM Plywood, Finland) on each loaded side of the specimens. The plywood plates were continuous without hole and the dowel loaded the wooden part only (Fig. 3a). The thickness of the reinforced specimens was $118 \mathrm{~mm}$.

- $10 \mathrm{~mm}$ OSB with hole: This test series is similar to the setup of $10 \mathrm{~mm} O S B$ without hole with the difference that the OSB plates also featured a half dowel hole and were loaded by the steel dowel as well. Thus, aside the reinforcement action, the OSB plates actively contribute to the embedding strength of these samples (Fig. 3b).

- $9 \mathrm{~mm}$ plywood with hole: This test series is similar to the setup of $9 \mathrm{~mm}$ plywood without hole with (a)
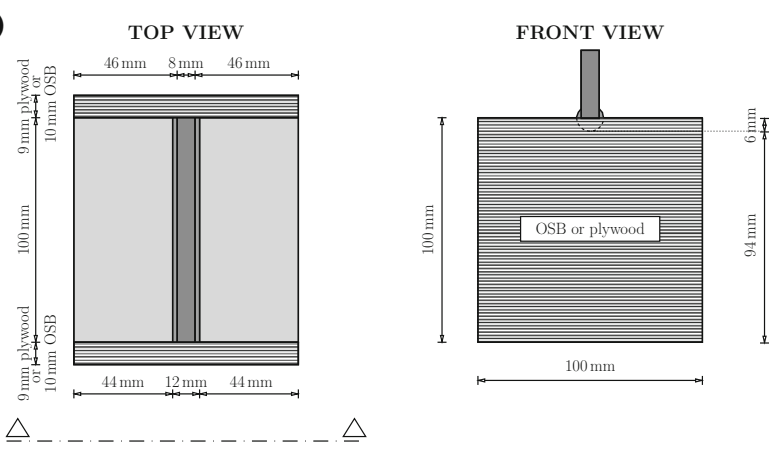

(b)
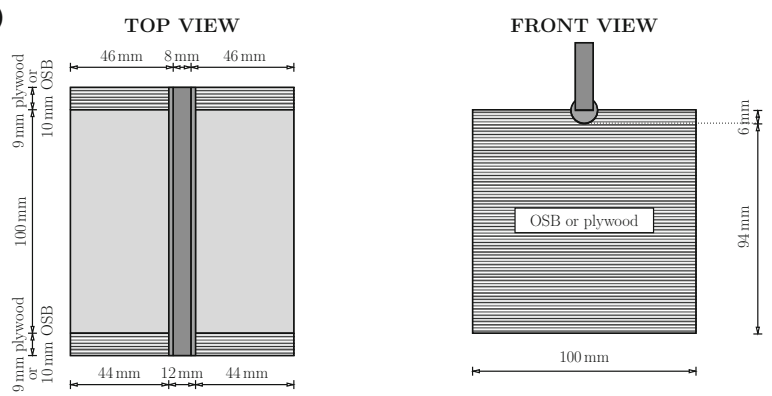

(c)
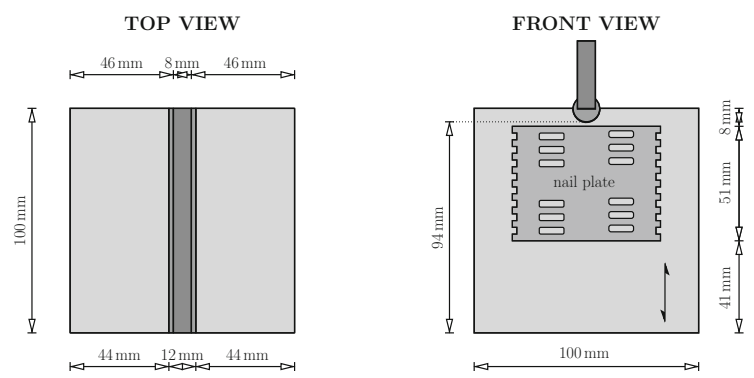

Fig. 3 Test specimens with surface reinforcements: a for series $10 \mathrm{~mm}$ OSB without hole and $9 \mathrm{~mm}$ plywood without hole; $\mathbf{b}$ for series $10 \mathrm{~mm}$ OSB with hole and $9 \mathrm{~mm}$ plywood with hole; $\mathbf{c}$ for series nail plate

the difference that the plywood plates also featured a half dowel hole and were loaded by the steel dowel as well. Thus, aside the reinforcement action, the plywood plates actively contribute to the embedding strength of these samples (Fig. 3b).

- Nail plate: Specimens in this test series were reinforced by nail plates (SIMPSON Strong-Tie $M P 24^{\circ}$, Simpson Strong-Tie Company Inc., USA) on each loaded side of the spcimens. The nail plates with the original dimensions of $102 \times 51 \mathrm{~mm}^{2}$ were cut off on both sides yielding dimensions of $50 \times 51 \mathrm{~mm}^{2}$, in order to prevent splitting on the sides of the wood specimens. The nail plates were then placed right below the hole for the dowel (Fig. 3c). 


\subsection{Testing procedure and deformation measurements}

Embedment tests were performed as compression tests and conducted on a triaxial servo-hydraulic testing machine, manufactured by Walter \& Bai, with a load cell of a maximum load of $250 \mathrm{kN}$. Tests were performed displacement-controlled with a loading rate of $1 \mathrm{~mm} / \mathrm{min}$ up to failure or up to a maximum displacement of $30 \mathrm{~mm}$. Additionally, 4 unloading and reloading cycles were executed with unloading at 5, 10, 15 and $30 \mathrm{kN}$. Only the unloading behavior at $15 \mathrm{kN}$ is evaluated and discussed herein. In order to eliminate creep deformations in the unloading behavior, the load levels were held constant for $30 \mathrm{~s}$ before unloading.

In addition to the internally measured displacements of the load unit, linear variable differential transformers (LVDT) HBM WA/50 mm-T (Hottinger Baldwin Messtechnik $\mathrm{GmbH}$, Austria) with a measuring length of $50 \mathrm{~mm}$ and a full-field deformation measurement device were used to measure the displacements of the dowel.

The full-field deformation measurement system was applied to all test series, except for series $10 \mathrm{~mm} O S B$ without hole and $9 \mathrm{~mm}$ plywood without hole, where LVDTs were used. The measurement system based on digital image correlation (DIC) enabled a full-field, noncontact and three-dimensional measurement of surface deformations. Two cameras were focused on the front and back face of the specimens, respectively. The system Q-400 from Dantec Dynamics (Neu-Ulm, Germany) including the evaluation software ISTRA 4D, with cameras of the type Stingray F-504 from Allied Vision Technologies (Stadtroda, Germany) with 5 MP CCD sensors (ICX655) and a resolution of $2452 \times 2056$ pixels, was used.

During testing, images from all four cameras were acquired every 2 seconds as long as the difference of the force from the triaxial servo-hydraulic testing machine between two images was lower than $5 \mathrm{kN}$. Such sudden changes in the applied force indicate the development and propagation of cracks, so that at those events images with the shortest possible interval were made to document these cracks sufficiently. The parameter values for the evaluation were set to the standard setting normal-good images with maximum permissible values for the accuracy of 0.1 pixels, the residuum of 20 gray values and the 3D residuum of 0.4 pixels. The facet size and the grid spacing deviated from the standard setting and were set in the range of 17 to 21 pixels, to allow for a uniform full-field evaluation.

The evaluation procedure is visualized in Fig. 4 and follows the corresponding standards for embedment testing (EN 383 2007; ASTM D5764-97a 2013). The displacement of the dowel was evaluated on both sides of the specimen

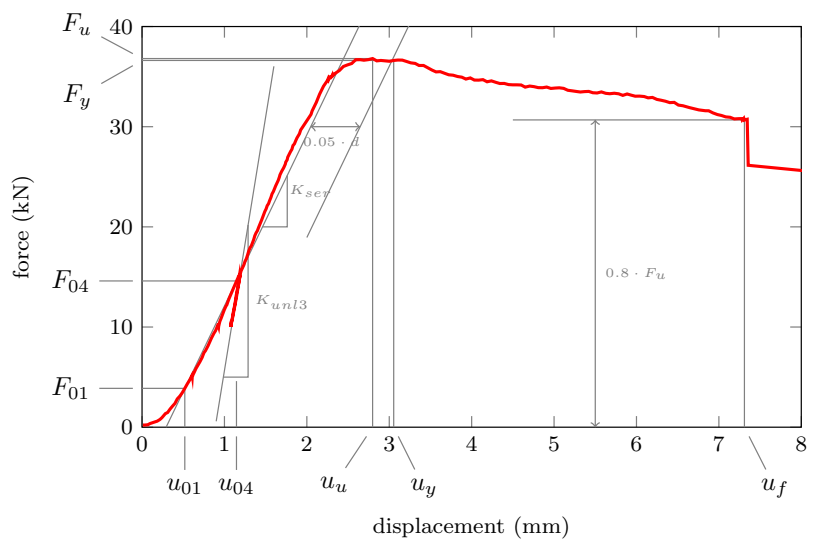

Fig. 4 Visualization of the derivation of parameters

by the full-field deformation measurement system. For specimens with reinforcing screws, a relative displacement of the steel dowel with respect to the unloaded wood was calculated based on the DIC measurements. This measure was not accessible for specimens with surface reinforcements, where LVDTs were used and thus, an (absolute) dowel displacement with respect to the rigid steel support was used instead. The corresponding mean value of the displacements was further used and plotted versus the vertical (loading) force. All load-displacement curves start with zero displacement at a load of $0.1 \mathrm{kN}$. $K_{\text {ser }}$ as the initial loading stiffness is evaluated between 0.1 and 0.4 times the maximum load $F_{u}$. The corresponding displacements are denoted $u_{01}, u_{04}$ and $u_{u}$. In addition to the maximum load, the yield load $F_{y}$ at an off-set of 0.05 times the dowel diameter is calculated with the corresponding displacement $u_{y}$. The maximum displacement is denoted $u_{f}$ and an unloading stiffness $K_{\text {unl } 3}$ is evaluated as the maximum gradient of the third unloading path. The ductility of the connection $D_{f}$ is calculated as the maximum displacement $u_{f}$ over the yield displacement $u_{y}$.

\section{Results and discussion}

Experimental results of clear wood specimens are presented with a special focus on embedment stresses, in relation to the different reinforcement measures. The embedment stress $\sigma_{h}$ in this context is defined as the average stress in the wood under the projected area of the steel dowel. Thus, it is calculated as the load divided by the dowel diameter $(12 \mathrm{~mm})$ and the thickness of the wood specimen.

The mean values (mean), as well as the standard deviation (SD) of all measured and calculated parameters are summarized in Table 1 for each test series. Tables with all 
Table 1 Overview of all tested specimens

\begin{tabular}{|c|c|c|c|c|c|c|c|c|}
\hline \multicolumn{9}{|l|}{ No reinforcement } \\
\hline & \multicolumn{2}{|c|}{ Unreinforced wood (displacement) } & \multicolumn{2}{|c|}{ Unreinforced wood (relative displacement) } & \multicolumn{2}{|c|}{ OSB plates } & \multicolumn{2}{|c|}{ Plywood panels } \\
\hline \multirow[t]{2}{*}{ Number of Samples } & 11 & & 11 & & 4 & & 4 & \\
\hline & Mean & SD & Mean & SD & Mean & SD & Mean & SD \\
\hline$\rho\left(\mathrm{kg} / \mathrm{m}^{3}\right)$ & 422 & 28 & 422 & 28 & 485 & 0 & 681 & 0 \\
\hline$F_{u}(\mathrm{kN})$ & 23.69 & 2.23 & 23.69 & 2.23 & 14.78 & 0.27 & 47.27 & 0.59 \\
\hline $\bar{\sigma}_{h, \max }$ & 19.75 & 1.86 & 19.75 & 1.86 & 24.24 & 0.95 & 88.25 & 1.32 \\
\hline$u_{u}(\mathrm{~mm})$ & 3.00 & 0.38 & 1.50 & 0.53 & 10.30 & 2.14 & 25.76 & 3.83 \\
\hline$F_{y}(\mathrm{kN})$ & 23.26 & 2.19 & 22.99 & 2.02 & 12.26 & 0.83 & 28.70 & 0.85 \\
\hline$u_{y}(\mathrm{~mm})$ & 2.70 & 0.35 & 1.22 & 0.32 & 1.94 & 0.41 & 2.18 & 0.03 \\
\hline$u_{f}(\mathrm{~mm})$ & 4.75 & 1.37 & 3.13 & 1.44 & 27.04 & 0.09 & - & - \\
\hline$K_{\text {ser }}(\mathrm{kN} / \mathrm{mm})$ & 12.92 & 1.24 & 55.14 & 16.60 & - & - & - & - \\
\hline$K_{\text {unl3 }}(\mathrm{kN} / \mathrm{mm})$ & 52.03 & 18.97 & 238 & 28 & - & - & - & - \\
\hline$D_{f}(-)$ & 1.81 & 0.65 & 2.75 & 1.43 & - & - & - & - \\
\hline
\end{tabular}

Dowel-type reinforcements

\begin{tabular}{|c|c|c|c|c|c|c|c|c|c|c|c|}
\hline \multirow{3}{*}{ Number of Samples } & \multicolumn{2}{|c|}{$2 \times 6 \mathrm{~mm} 2 d$} & \multicolumn{2}{|c|}{$1 \times 8 \mathrm{~mm} 2 d$} & \multicolumn{2}{|c|}{$2 \times 8 \mathrm{~mm} 2 d$} & \multicolumn{3}{|c|}{$2 \times 6 \mathrm{~mm}$ contact } & \multicolumn{2}{|c|}{$1 \times 8 \mathrm{~mm}$ contact } \\
\hline & \multicolumn{2}{|l|}{12} & \multicolumn{2}{|l|}{12} & \multicolumn{2}{|l|}{10} & \multicolumn{3}{|l|}{12} & \multicolumn{2}{|l|}{12} \\
\hline & Mean & SD & Mean & SD & Mean & SD & Mean & \multicolumn{2}{|c|}{ SD } & Mean & SD \\
\hline$\rho\left(\mathrm{kg} / \mathrm{m}^{3}\right)$ & 430 & 33 & 433 & 30 & 453 & 42 & 433 & \multicolumn{2}{|c|}{30} & 430 & 27 \\
\hline$F_{u}(\mathrm{kN})$ & 33.81 & 4.10 & 36.83 & 4.32 & 38.02 & 4.63 & 39.25 & \multicolumn{2}{|c|}{2.81} & 36.80 & 3.89 \\
\hline $\bar{\sigma}_{h, \max }$ & 27.12 & 2.81 & 30.05 & 4.89 & 26.54 & 3.47 & 32.11 & \multicolumn{2}{|c|}{2.99} & 29.69 & 4.69 \\
\hline$u_{u}(\mathrm{~mm})$ & 4.64 & 6.26 & 1.72 & 0.45 & 15.19 & 8.85 & 6.92 & \multicolumn{2}{|c|}{1.84} & 2.92 & 0.70 \\
\hline$F_{y}(\mathrm{kN})$ & 32.16 & 2.83 & 36.29 & 4.10 & 31.35 & 3.36 & 34.76 & \multicolumn{2}{|c|}{4.73} & 33.30 & 4.49 \\
\hline$u_{y}(\mathrm{~mm})$ & 1.60 & 0.24 & 1.69 & 0.48 & 1.70 & 0.38 & 2.94 & \multicolumn{2}{|c|}{1.13} & 1.92 & 0.36 \\
\hline$u_{f}(\mathrm{~mm})$ & 12.13 & 6.82 & 5.88 & 1.59 & 21.88 & 9.93 & 10.79 & \multicolumn{2}{|c|}{2.49} & 7.86 & 2.00 \\
\hline$K_{\text {ser }}(\mathrm{kN} / \mathrm{mm})$ & 48.84 & 15.20 & 56.82 & 32.15 & 46.45 & 24.37 & 23.18 & \multicolumn{2}{|c|}{10.59} & 40.72 & 18.62 \\
\hline$K_{\text {unl3 }}(\mathrm{kN} / \mathrm{mm})$ & 234 & 36 & 195 & 86 & 275 & 102 & 199 & \multicolumn{2}{|c|}{59} & 239 & 98 \\
\hline$D_{f}(-)$ & 7.81 & 5.01 & 3.64 & 0.98 & 12.95 & 6.28 & 4.40 & \multicolumn{2}{|c|}{2.68} & 4.21 & 1.28 \\
\hline \multicolumn{12}{|c|}{ Surface reinforcements } \\
\hline & \multicolumn{3}{|c|}{$10 \mathrm{~mm}$ OSB without hole } & \multicolumn{2}{|c|}{$\begin{array}{l}9 \mathrm{~mm} \text { plywood } \\
\text { without hole }\end{array}$} & \multicolumn{2}{|c|}{$\begin{array}{l}10 \mathrm{~mm} O S B \\
\text { with hole }\end{array}$} & \multicolumn{2}{|c|}{$\begin{array}{l}9 \mathrm{~mm} \text { plywood } \\
\text { with hole }\end{array}$} & \multicolumn{2}{|c|}{ Nail plate } \\
\hline Number of Samples & 12 & & & 11 & & 12 & & 12 & & 11 & \\
\hline & Mean & & & Mean & SD & Mean & SD & Mean & SD & Mean & SD \\
\hline$\rho\left(\mathrm{kg} / \mathrm{m}^{3}\right)$ & 426 & 2 & & 421 & 24 & 421 & 25 & 424 & 23 & 456.62 & 37.073 \\
\hline$F_{u}(\mathrm{kN})$ & 28.95 & & & 29.33 & 3.54 & 34.40 & 3.77 & 40.69 & 2.70 & 35.84 & 3.57 \\
\hline $\bar{\sigma}_{h, \max }$ & 23.83 & & & 22.67 & 6.69 & 27.61 & 4.14 & 33.17 & 2.72 & 29.38 & 3.54 \\
\hline$u_{u}(\mathrm{~mm})$ & 2.60 & & & 3.04 & 0.46 & 3.61 & 0.71 & 4.37 & 0.82 & 3.71 & 0.41 \\
\hline$F_{y}(\mathrm{kN})$ & 28.19 & & & 28.93 & 3.63 & 33.08 & 3.62 & 40.28 & 2.44 & 34.30 & 3.40 \\
\hline$u_{y}(\mathrm{~mm})$ & 2.22 & & & 2.74 & 0.32 & 3.51 & 0.74 & 4.31 & 0.82 & 3.07 & 0.58 \\
\hline$u_{f}(\mathrm{~mm})$ & 14.87 & & & 21.69 & 8.61 & 10.14 & 2.22 & 27.02 & 9.30 & 13.27 & 4.74 \\
\hline$K_{\text {ser }}(\mathrm{kN} / \mathrm{mm})$ & 22.81 & & & 18.16 & 3.66 & 14.23 & 2.11 & 13.26 & 3.69 & 17.45 & 4.70 \\
\hline$K_{\text {unl3 }}(\mathrm{kN} / \mathrm{mm})$ & 128.77 & & 45 & 80.43 & 24.83 & 33.11 & 3.99 & 42.48 & 22.35 & 42.83 & 7.05 \\
\hline$D_{f}(-)$ & 6.80 & & & 8.00 & 3.52 & 3.00 & 0.84 & 6.61 & 2.76 & 4.26 & 0.94 \\
\hline
\end{tabular}


(a)

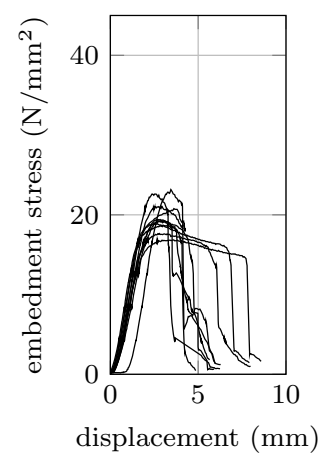

(b)

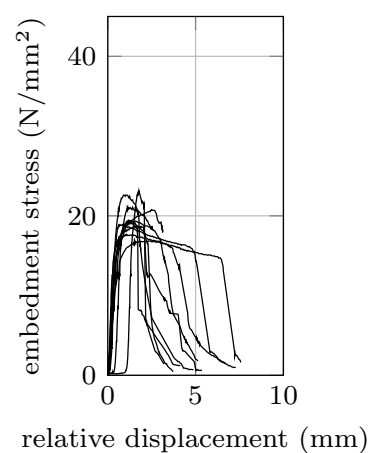

(c)

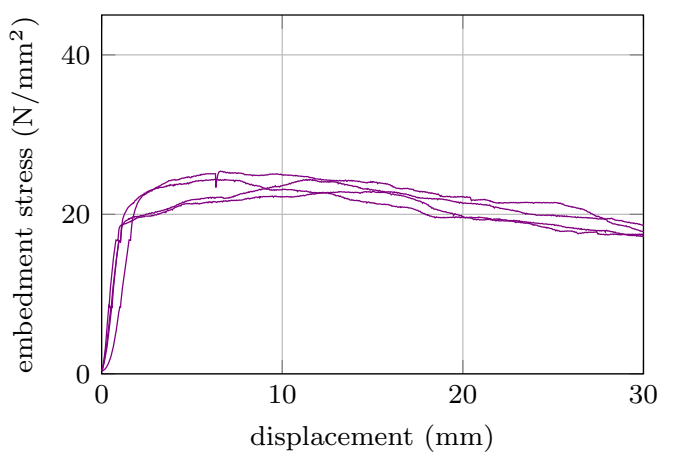

(d)

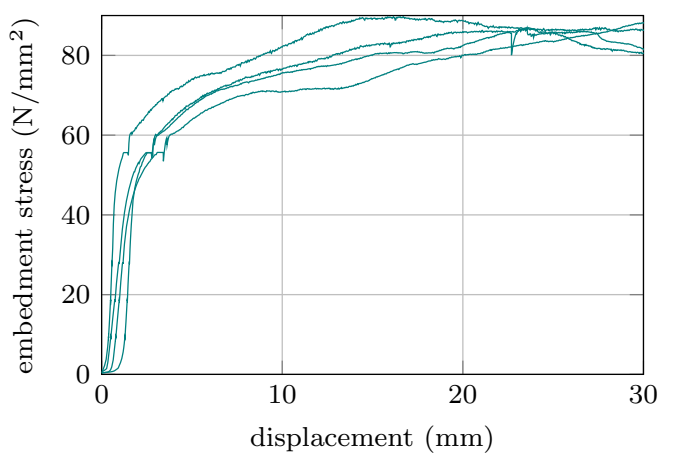

Fig. 5 Embedment stress-displacement curves for unreinforced reference test series: a unreinforced wood; b unreinforced wood; c OSB; d plywood

parameter values for every single experiment are available in Online Resource 1.

Embedment stress-displacement curves in combination with surface strains perpendicular to the grain $\left(\varepsilon_{x x}\right)$ were evaluated as well. This allowed assessing the influence of the reinforcement with different types of screws on the crack evolution and propagation. The initial crack was always detected right below the dowel and, in most cases, prior to the maximum embedment stress. Crack propagation depended on the type of reinforcement.

In general, compared to the reference setup of an unreinforced wood specimen, all types of reinforcements studied herein increased the bearing capacity of the steel dowel and increased the ductility of the embedment test setup. Their individual characteristics are discussed in the following.

\subsection{Unreinforced reference specimens}

As expected, unreinforced wood specimens of the reference test series failed due to splitting as a reason of tensile stresses perpendicular to the grain due to the wedge action of the dowel. This brittle failure corresponds to the sudden drop of the embedment stress curve of this test series (Fig. 5a). The onset of cracking started right below the dowel at about 85-95\% of the maximum embedment stress. The crack under the steel dowel propagated through the entire specimen and, consequently, further load transfer was impossible. The maximum embedment stress $\sigma_{h, \max }$ of these samples was reached in between a dowel displacement of 2 to $4 \mathrm{~mm}$ and the mean value of these maximum embedment stresses $\bar{\sigma}_{h, \max }$ amounted to $19.8 \mathrm{~N} / \mathrm{mm}^{2}$ (Table 1). The value of $19.8 \mathrm{~N} / \mathrm{mm}^{2}$ seems to be low compared to previously published research data, see for example Sandhaas et al. (2013). Reasons for this might be found in the ASTM test setup. Additionally, Sandhaas et al. (2013) revealed an influence of the steel quality, which was most probably related to the surface roughness. The strong effect of the steel dowel surface roughness was also shown by Sjödin et al. (2008). Another effect that might contribute to a higher risk for splitting is the rather large width of the test specimen. A pronounced yield behavior was missing, though the behavior of some specimens suggested the onset of yielding with dowel displacements of up to $8 \mathrm{~mm}$.

Fig. 5a and $\mathrm{b}$ show the strong effect of the deformation of the wood specimen when evaluating the stiffness of the test setup. Using a relative displacement of the steel dowel gave a stiffness value more than four times the stiffness using the absolute displacement.

On the contrary, the engineered wood products used as surface reinforcements in the subsequently described test series, exhibited a pronounced yield behavior under embedment testing. Both OSB and plywood showed this characteristic up to dowel displacements of $30 \mathrm{~mm}$ (Fig. 5c, d). This is explained by the inherent reinforcement of these materials due to cross-layers of wood strands and veneers, respectively. The mean value of the maximum embedment stresses $\bar{\sigma}_{h, \max }$ amounted to $24.2 \mathrm{~N} / \mathrm{mm}^{2}$ for OSB and to $88.3 \mathrm{~N} / \mathrm{mm}^{2}$ for plywood (Table 1). As for OSB, the maximum embedment stress $\sigma_{h, \max }$ was observed at dowel displacements of $11.3 \mathrm{~mm}$, while a continuous increase of the embedment stress up to $30 \mathrm{~mm}$ dowel displacement was found for plywood. The latter is an effect 
(a)

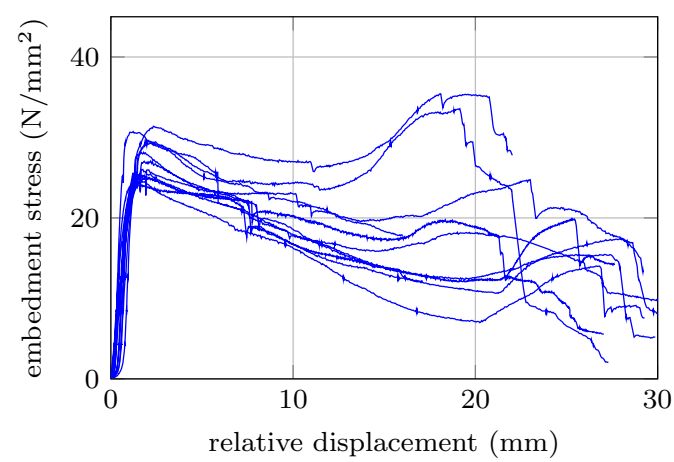

(c)

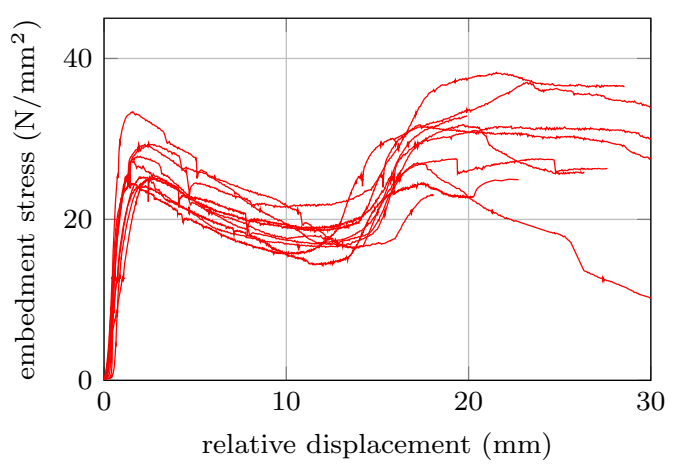

(e)

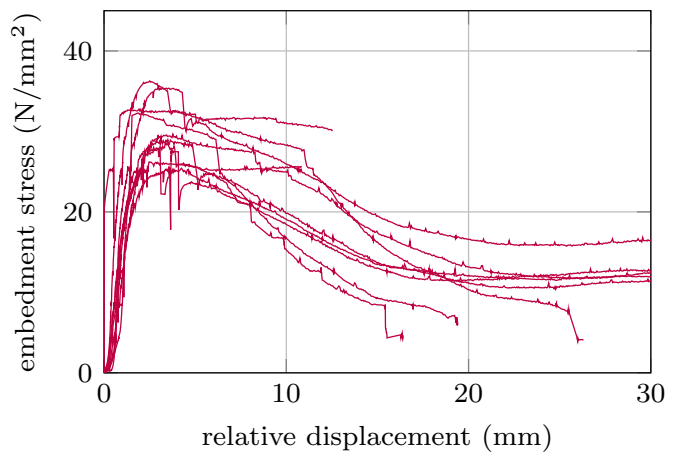

(b)

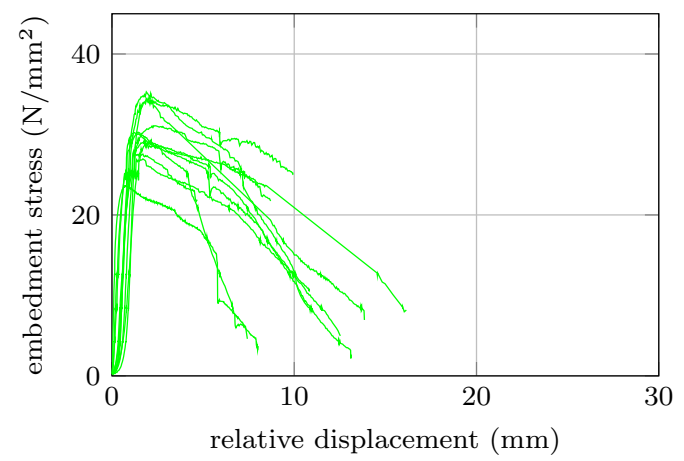

(d)

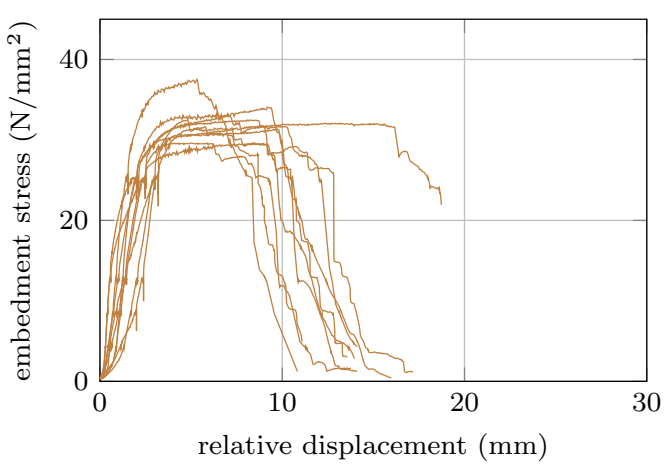

Fig. 6 Embedment stress-displacement curves for test series with dowel-type reinforcements: a $2 \times 6 \mathrm{~mm} 2 \mathrm{~d}$; b $1 \times 8 \mathrm{~mm} 2 \mathrm{~d}$; c $2 \times 8 \mathrm{~mm} 2 \mathrm{~d}$; d $2 \times 6 \mathrm{~mm}$ contact; e $1 \times 8 \mathrm{~mm}$ contact

of the continuous veneer cross-layers, which are loaded perpendicular to the grain. The corresponding embedment behavior perpendicular to the grain shows a pronounced hardening effect due to a rope effect in the wood fibers as well as a compressed timber volume (see e.g. Schoenmakers and Svensson 2011).

\subsection{Dowel-type reinforcements}

Specimen-specific embedment curves of wood reinforced with different types, position and number of screws are illustrated in Fig. 6. A comparison of mean embedment stress-displacement curves for the test series reinforced with screws is shown in Fig. 7.

Three test series with different types and numbers of screws positioned $2 \mathrm{~d}$ below the dowel were conducted $(2 \times 6 \mathrm{~mm} 2 d, 1 \times 8 \mathrm{~mm} 2 d \& 2 \times 8 \mathrm{~mm} 2 d)$. The corresponding embedment stress-displacement relationships are illustrated in Fig. 6a-c. Compared to the unreinforced situation, the reinforcing screws increased the mean value of the maximum embedment stresses $\bar{\sigma}_{h, \max }$ to 27.1 and $26.5 \mathrm{~N} / \mathrm{mm}^{2}$ for $2 \times 6 \mathrm{~mm} 2 d$ and $2 \times 8 \mathrm{~mm} 2 d$ 


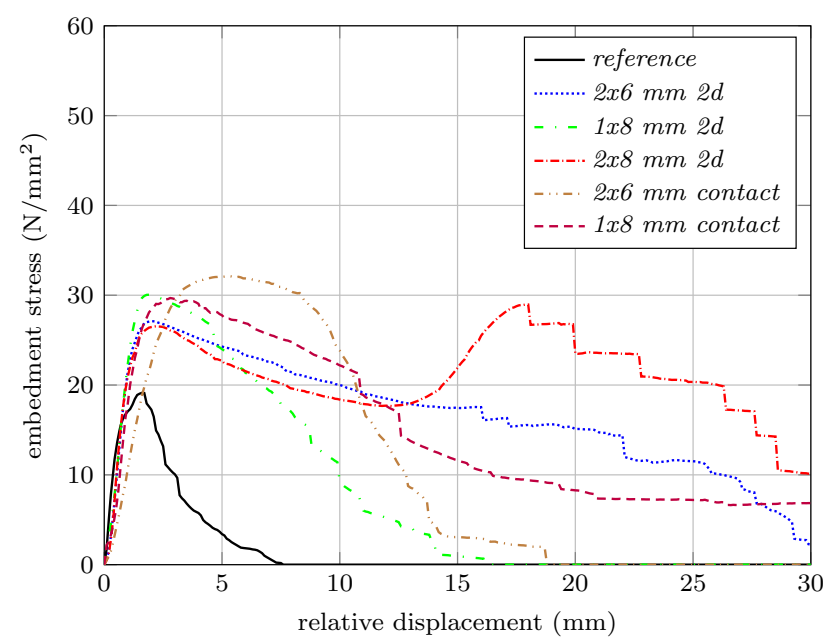

Fig. 7 Compilation of mean embedment curves for series with dowel-type reinforcements

respectively (Table 1). For the test series $1 \times 8 \mathrm{~mm} 2 d$ the mean value of the maximum embedment stresses $\bar{\sigma}_{h, \max }$ even increased to $30.1 \mathrm{~N} / \mathrm{mm}^{2}$. The relative small differences in the mean maximum embedment stress for these three different test series indicate that the corresponding types of screws, their dimensions, number and position, are equally well capable of taking the occurring splitting forces.

The different number and dimensions of screws positioned $2 \mathrm{~d}$ below the dowel take effect on the structural behavior at increased dowel displacements. After a stress peak, at a displacement between 2.1 and $3.7 \mathrm{~mm}$ (Fig. 7), a softening behavior in the stress-displacement curves was encountered. This is due to the fact that vertical cracks right below the dowel occured. Despite these cracks there were no sudden stress drops, as observed in unreinforced specimens. The softening behavior was strongest for test series $1 \times 8 \mathrm{~mm} 2 d$, where failure of the specimens occurred at dowel displacements of about 10 to $12 \mathrm{~mm}$. Thus, a single screw with a diameter of $8 \mathrm{~mm}$ could obviously not take the splitting force.

A different behavior at large dowel displacements was found for the test series with 2 screws $(2 \times 6 \mathrm{~mm} 2 d$ and $2 \times 8 \mathrm{~mm} 2 d$ ). After the stress peak at dowel displacements of 2.8 to $4.4 \mathrm{~mm}$ the embedment stress curves showed a slight decrease for both test series. This decline of the curves continued up to a displacement of 13 to 14 $\mathrm{mm}$. At this point, specimens of the test series $2 \times 8 \mathrm{~mm} 2 d$ and some specimens of the test series $2 \times 6 \mathrm{~mm} 2 d$ started to take up load again and, consequently, the embedment stress increased. This is due to the fact that the dowel got in contact with the screws. Thus, screws did not only absorb the splitting forces perpendicular to the grain, but they were also directly loaded by the dowel. Therefore, additional embedment stresses under the screws occured and, even more, additional tensile forces due to the bending of the screw developed. These individual load transfer mechanisms added to the embedment stress of the dowel and led to an overall increase of the embedment stress. This phenomenon was particularly pronounced for specimens of series $2 \times 8 \mathrm{~mm} 2 d$, while an onset of this phenomenon was visible in series $2 \times 6 \mathrm{~mm} 2 d$. Specimens of the latter test series tended to crack at displacements of 7 up to $12 \mathrm{~mm}$, while no (continuous) cracks were observed in test series $2 \times 8 \mathrm{~mm} 2 d$ up to displacements of about $5 \mathrm{~mm}$. Moreover, brittle tensile failure of screws in series $2 \times 6 \mathrm{~mm} 2 d$ was the reason for final failure.

Evaluation of crack propagation is exemplarily illustrated for one specimen of the test series $2 \times 6 \mathrm{~mm} 2 d$ in Fig. 8. For specimens reinforced with two screws at a distance of $2 \mathrm{~d}$ $(2 \times 6 \mathrm{~mm} 2 d$ and $2 \times 8 \mathrm{~mm} 2 d)$ the first crack evolved at a larger displacement of the dowel and closer to the maximum embedment stress compared to the reference specimens. The crack then propagated downwards until it reached the screws at a displacement of the dowel of about $5 \mathrm{~mm}$. At this displacement the crack of the reference specimens typically already reached the bottom of the specimen, which initiated complete failure. Hence the reinforcement with two screws at a distance of $2 \mathrm{~d}$ leads to a stable crack growth. When the crack reached the bottom of the specimens, a load drop of about 3-4 N/mm ${ }^{2}$ was observed in the load-displacement curves. However, this did not initiate complete failure of the entire specimen. Crack evolution and propagation of the $1 \times 8 \mathrm{~mm} 2 d$ test series however were more similar to the reference specimens than to the specimens reinforced with two screws at a distance of $2 \mathrm{~d}$. In this case, the first crack evolved at about $95 \%$ of the maximum embedment stress. The crack then propagated downward and reached the screw shortly after the maximum embedment stress was reached. At a displacement of about $5 \mathrm{~mm}$ of the dowel the crack reached the bottom of the specimen.

Two test series with screws in contact with the dowel were conducted $(2 \times 6 \mathrm{~mm}$ contact, see Fig. $6 \mathrm{~d}$, and $1 \times 8 \mathrm{~mm}$ contact, see Fig. 6e). As outlined above, the screws in these test series were directly loaded by the dowel in addition to the loading they received acting as a lateral reinforcement. Thus, embedment stresses in the wood under the screw and tensile stresses in the axial direction of the screw developed. As a consequence, the observed embedment stresses were slightly higher compared to the other test series with screws $2 \mathrm{~d}$ below the dowel. Strictly speaking, the strength of these test specimens should not be denoted embedment strength since actually a connection system was tested. The maximum stress was found at slightly larger dowel displacements of 5.0-7.5 mm (Fig. 7) compared to an overall mean dowel displacement of $3.0 \mathrm{~mm}$ for the other test 


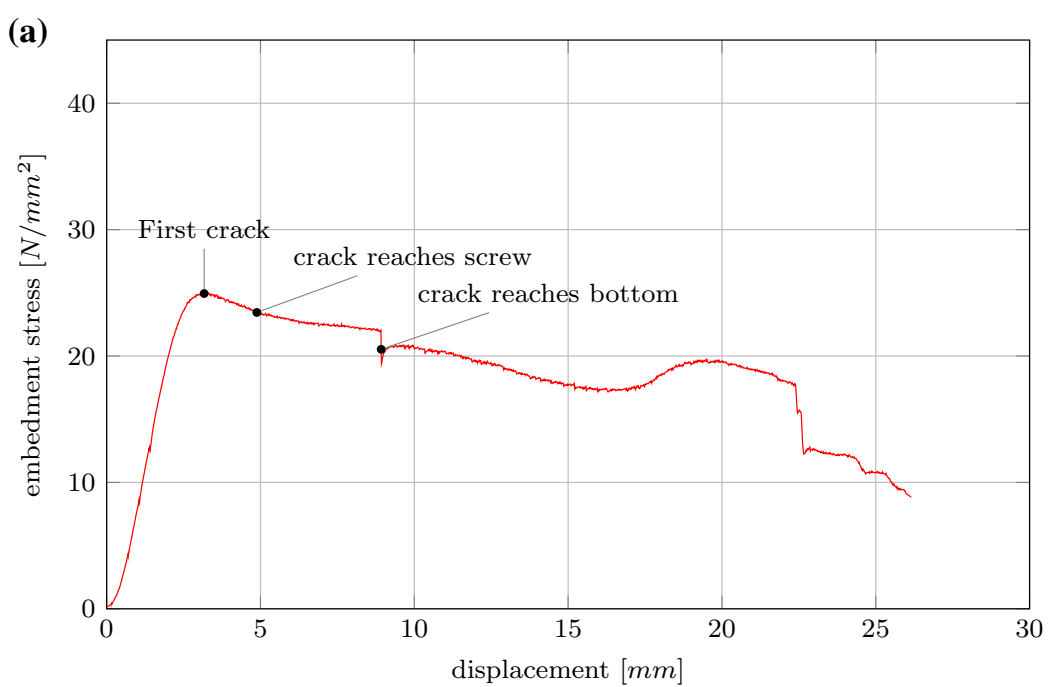

(b)

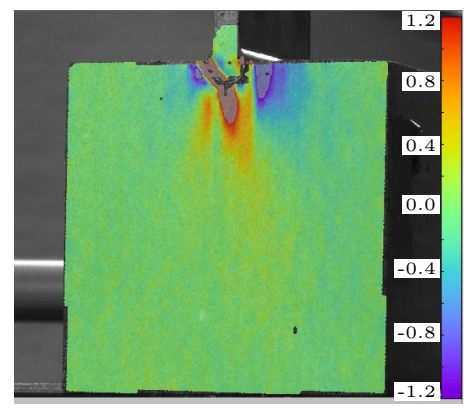

(c)

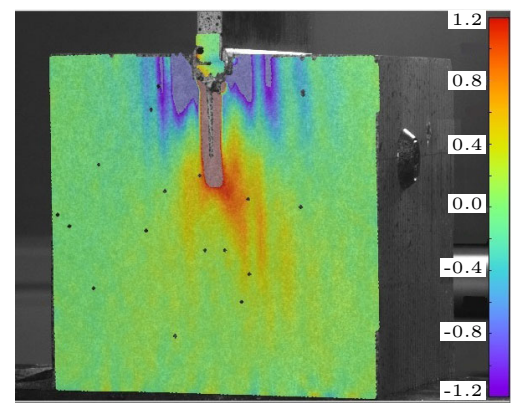

(d)

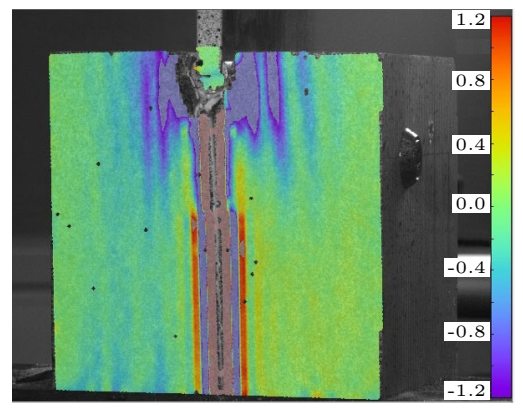

Fig. 8 Strain fields of surface strains perpendicular to the grain $\varepsilon_{x x}$ (\%) obtained from DIC for the identification of crack evolution for $2 \times 6 \mathrm{~mm} 2 d$ : a exemplary embedment stress-dowel displacement curve for test series $2 \times 6 \mathrm{~mm} 2 d$; b First crack $(3.17 \mathrm{~mm}$ dowel

series with screws. Failure of the two test series with screws in contact with the dowel was initiated by a brittle failure of screws with a diameter of $6 \mathrm{~mm}$ and by a withdrawal failure of the screw with a diameter of $8 \mathrm{~mm}$, respectively. Thus, the two configurations allowed for a limited ductility of the test setup.

Only minor variations in the stiffness of specimens with reinforcing screws were found (see Fig. 7). Reinforced specimens did not exhibit a higher stiffness even for specimens with screws in contact with the dowel.

For the specimens of the test series $2 \times 6$ mm contact the first crack could be identified in the DIC images close to the yield force at a dowel displacement of about 4-6 mm. After the crack initiation a stable crack growth could be observed until the crack reached the bottom of the specimen at a dowel displacement above $10 \mathrm{~mm}$. The complete cracking of the whole specimen initiated overall failure of the specimen, as shortly afterwards the screws experienced a brittle failure as well. The cracking of the specimens of the test series displacemet); c Crack reached the screws $(4.88 \mathrm{~mm}$ dowel displacement); $\mathbf{d}$ crack reached the bottom of the sample $(8.92 \mathrm{~mm}$ dowel displacement)

$1 \times 8 \mathrm{~mm}$ contact was decisively different. There were two reasons for this. Firstly, $8 \mathrm{~mm}$ screws had a more ductile behavior then $6 \mathrm{~mm}$ screws. The second reason was that one screw right in the middle of the specimen was not capable of preventing the propagation of cracks equally well as two screws. Therefore, the first crack appeared at a dowel displacement of 3 to $4 \mathrm{~mm}$, clearly before the maximum embedment stress was reached. Additionally, the crack growth was not as stable as the one from the test series $2 \times 6 \mathrm{~mm}$ contact and reached the bottom of the specimen at a dowel displacement of 6-7 mm.

\subsection{Surface reinforcements}

Specimen-specific embedment curves of wood specimens reinforced on the surface with different types of engineered wood products and nail plates are illustrated in Fig. 9. A comparison of mean embedment stress-displacement curves for the same test series is shown in Fig. 10. 
(a)

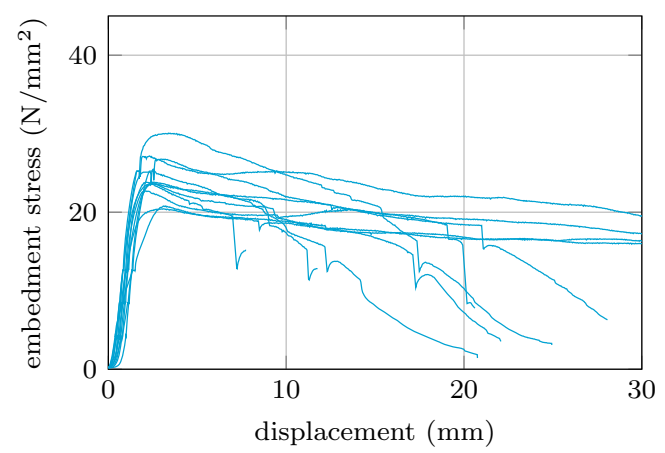

(c)

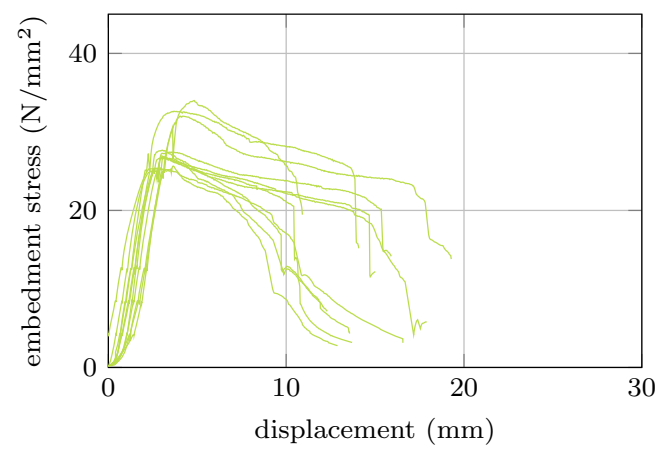

(e)

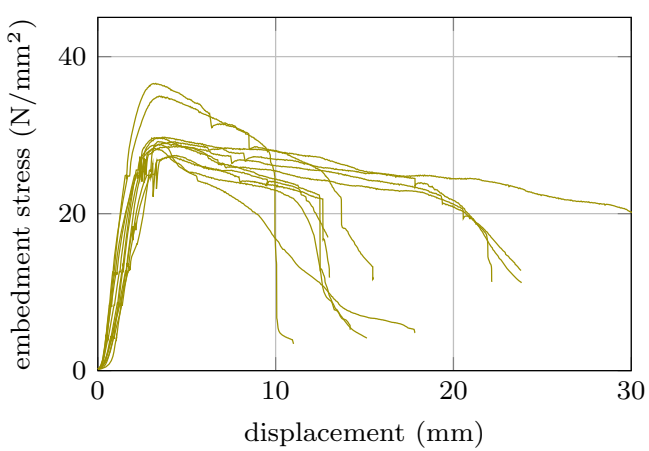

(b)

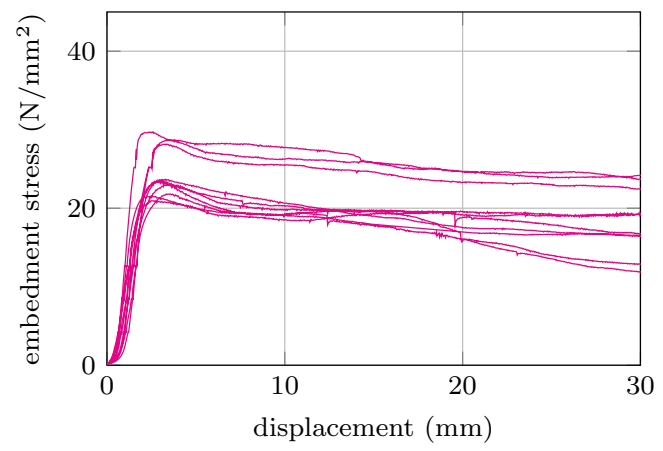

(d)

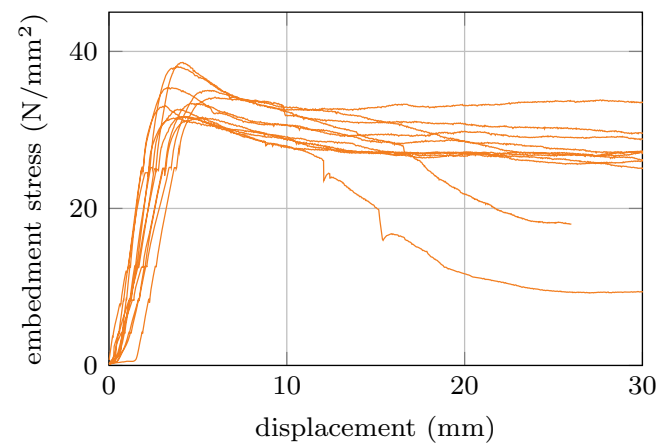

Fig. 9 Embedment stress-displacement curves for test series with surface reinforcements: a $10 \mathrm{~mm}$ OSB without hole; $\mathbf{b} 9 \mathrm{~mm}$ plywood without hole; c $10 \mathrm{~mm}$ OSB with hole; d $9 \mathrm{~mm}$ plywood with hole; e nail plate

In two test series, engineered wood products were used as surface reinforcement with the dowel only loading the wood specimen $(10 \mathrm{~mm}$ OSB without hole and $9 \mathrm{~mm}$ plywood without hole). For both test series, the embedment stress-dowel displacement relationships showed a very ductile behavior (Fig. 9a, b). The corresponding mean value of the maximum embedment stresses $\bar{\sigma}_{h, \max }$ of 23.8 and $22.7 \mathrm{~N} / \mathrm{mm}^{2}$ were observed at dowel displacements of 2.6 and $3.0 \mathrm{~mm}$ for the tests with OSB and plywood reinforcement, respectively (Table 1). Thus, as compared to the reference wood specimens, a slightly higher embedment stress was found. Some of the OSB reinforced specimens failed due to a tension failure of the OSB plates, while plywood panels showed no failure up to a dowel displacement of $30 \mathrm{~mm}$.

A different overall behavior was observed for specimens with OSB and plywood reinforcement, where the reinforcement was additionally loaded by the dowel $(10 \mathrm{~mm}$ OSB with hole, see Fig. 9c, and $9 \mathrm{~mm}$ plywood with hole, see Fig. 9d). In this case, the embedment stresses were calculated as the average stress over the entire thickness of the test specimen, i.e. 118 and $120 \mathrm{~mm}$, respectively. The corresponding mean values of the maximum embedment stresses $\bar{\sigma}_{h, \max }$ were considerably higher compared to the other test series with surface reinforcement and amounted to 27.6 and $33.2 \mathrm{~N} / \mathrm{mm}^{2}$ at dowel displacements of 4.4 and 


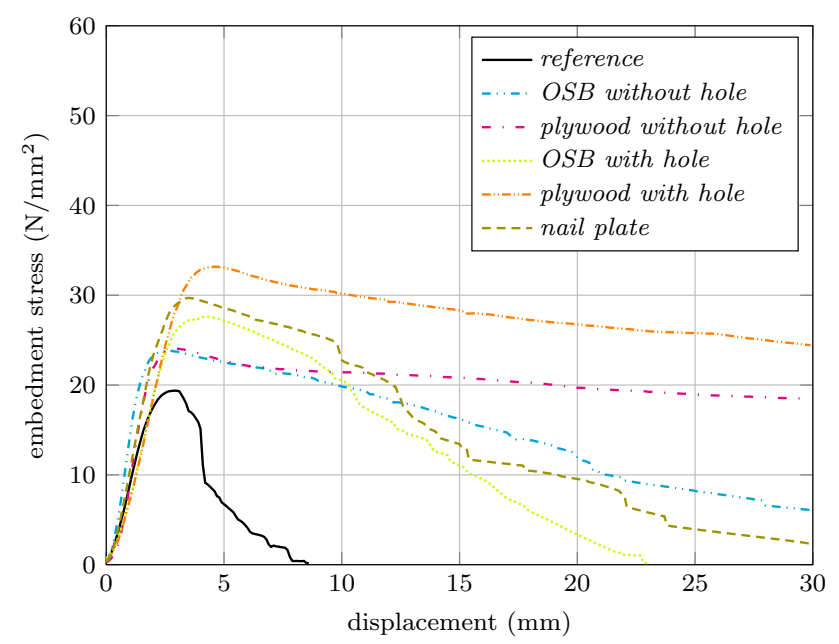

Fig. 10 Compilation of mean embedment curves for series with surface reinforcements

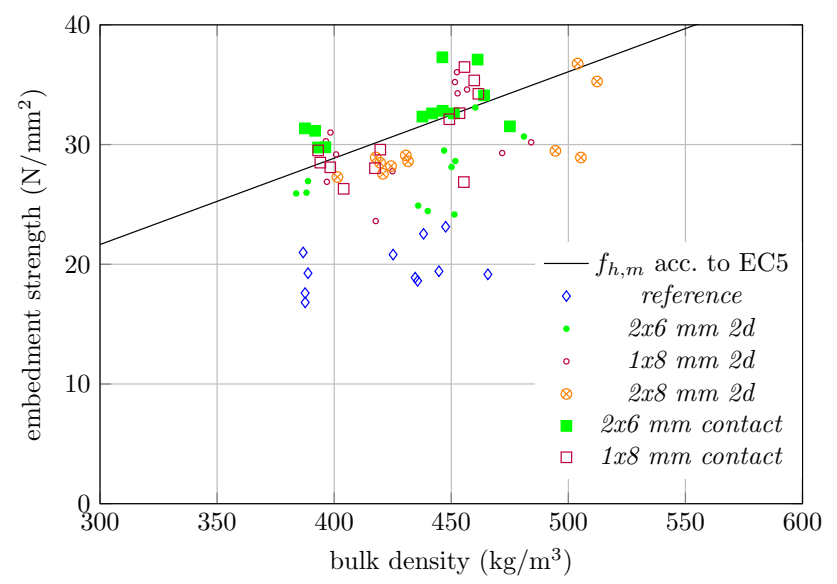

Fig. 11 Embedment strength of dowel-type reinforced specimens compared with the embedment strength according to Eurocode 5

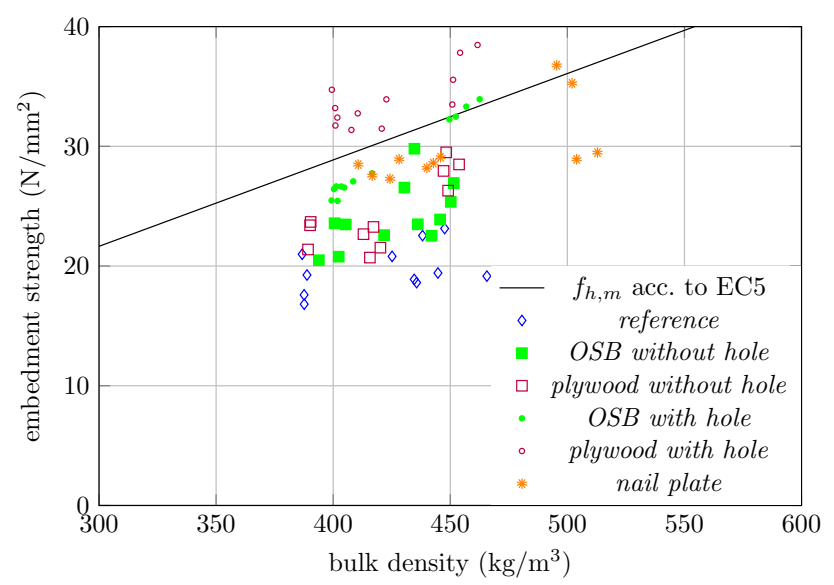

Fig. 12 Embedment strength of surface-reinforced specimens compared with the embedment strength according to Eurocode 5
$3.6 \mathrm{~mm}$ for the OSB and plywood reinforced samples, respectively (Table 1). Due to the parallel setup of the individual layers, namely wood and OSB or plywood, respectively, the higher yield strength in the embedment behavior of plywood increased the stresses in the reinforced test setup. As regards the OSB reinforced specimens, the additional loading caused crushing of the OSB plates, which led to a severe damage and, consequently, to failure of the reinforcing plates. However, a slightly increased embedment strength was observed. Failure of the corresponding specimens is observed at displacements of about $9.0-17.5 \mathrm{~mm}$. On the contrary, there was no failure of the plywood reinforced wood specimens.

The behavior of the specimens reinforced with nail plates was comparable to the test series $9 \mathrm{~mm} O S B$ with hole. Similar to the test series discussed before, due to the positioning close to the steel dowel, nail plates were loaded by the dowel. Thus, a slightly higher embedment stress compared to test series $9 \mathrm{~mm}$ OSB without hole and $10 \mathrm{~mm}$ plywood without hole, was observed. The mean value of the maximum embedment stresses $\bar{\sigma}_{h, \max }$ was $29.4 \mathrm{~N} / \mathrm{mm}^{2}$ (Table 1). The subsequent failure behavior was comparable to the test series $9 \mathrm{~mm} O S B$ with hole and failure was observed at displacements of about $10 \mathrm{~mm}$. Due to the loading of the nail plate, it started to bend outwards and thus, the nails were pushed out of the wood. As a consequence, transversal tension forces due to the embedment of the steel dowel could not be transferred and the wooden specimen started to split.

\subsection{Comparison of experimental results with Eurocode 5}

The embedment strength determined in the experiments is compared to the embedment strength for dowel connections according to EN 1995-1-1 (2004). Following the definitions of EN 383, the embedment strength $f_{h}$ from the experiments is determined as the maximum embedment stress or the embedment stress at a maximum displacement of $5 \mathrm{~mm}$, respectively. On the other hand, the equation in Eurocode 5 for calculation of the embedment strength of dowels reads as

$f_{h}=0.082 \cdot(1-0.01 \cdot d) \cdot \rho$,

with $d$ as the dowel diameter and $\rho$ as the mass density of wood. Since individual test results are directly compared, the corresponding (mean) values of the dowel diameter $\mathrm{d}=$ $12 \mathrm{~mm}$ and of the specimen-specific density $\rho$ are used in Eq.(1).

The comparison of experimental data obtained in this study and results of the Eurocode 5 based calculations is shown in Figs. 11 and 12. The measured embedment 
strength of the unreinforced specimens lies considerably below and amounts to about $65 \%$ of the values suggested by Eurocode 5. Possible reasons might be found in the particular test setup, the surface roughness of the steel dowel and the comparably large width of the test specimens. On the contrary, the values determined for doweltype reinforced specimens are very close to the Eurocode 5 values. Thus, reinforcements can be considered an appropriate measure to avoid premature splitting of the specimen and thus, to ensure the determination of a plastic property that will be further used in the calculation of the (plastic) connection strength by means of the European yield model.

Slightly higher embedment strength is found for the screws-reinforcement directly below (in contact with) the dowels, while the trend line for screws-reinforcement $2 \mathrm{~d}$ below the dowel is very close to the relationship given in Eurocode 5.

As for surface-reinforced specimens, strength properties determined in the experiments are lower than corresponding Eurocode 5 values, but higher compared to the unreinforced reference specimens. The strength is increased to values close to or even above Eurocode 5, in case of an additional loading of the reinforcement layers and in case of reinforcement with nail plates.

\section{Conclusion and future work}

A comprehensive series of experiments was carried out in order to investigate the influence of different types of reinforcements for dowel-type timber connections on the embedment behavior of wood parallel to the grain. For this purpose, a test setup according to ASTM D5764-97a (2013) was chosen, since this testing procedure is particularly prone to splitting of the wood. Clear wood specimens were reinforced with different types and numbers of screws, different engineered wood products and nail plates.

Test results underline the high potential of these reinforcement techniques for an increased ductility of doweltype connections. Unreinforced wood failed due to splitting, at dowel displacements of less than $5 \mathrm{~mm}$, while displacements of up to $30 \mathrm{~mm}$ were possible with several different reinforcements. The comparison of reinforced and unreinforced specimens suggests a premature failure of the unreinforced wood and consequently, an underestimation of the actual embedment strength. For this reason, embedment strength of reinforced specimens was higher compared to the unreinforced situation. This was supported by the investigation of cracks on the surface of the specimens using a full-field deformation measurement system.

It could be demonstrated that the embedment strength even further increases if the reinforcement elements actively contribute to the load transfer. Therefore, the embedment strength in case of screws with contact to a dowel, in case of engineered wood products on the surfaces and in case of nail plates loaded by the dowel, was higher than for other reinforcements. For screws with a distance to the dowel, a delayed contribution to the load transfer was observed. If the load is at least partially transmitted through the reinforcement, the strength clearly has to be regarded as a structural property not only taking embedding into account. Number, type and position of screws affected the post-failure behavior and the ductility of the test setup to different extents. Thus, a higher number of thicker screws yielded higher ductility of the connection. On the contrary, no clear trend for higher stiffness in case of screws in contact with the dowel was found in this experimental investigation.

The embedment strength determined on unreinforced specimens was found to be low when compared with embedment strength values according to EN 1995-1-1 (2004), since premature splitting of the specimen occurred before considerable plastic deformations in the wood underneath the dowel could develop. In the design of connections using the European yield model, the embedment strength is used as a plastic material characteristic, which should therefore be determined in a corresponding test setup. The ductile material response of wood under embedment stresses should be separated from setup-specific brittle failure modes, even for large dowel displacements. Contrary to the unreinforced specimens, embedment strength determined with reinforcements was close to or even higher than Eurocode 5 values. The strength determined with reinforcements in contact with the dowel should however be considered as strength of a connection system rather than an embedment characteristic.

The test data illustrate the potential of reinforcements in the determination of embedment characteristics up to high dowel displacements, even in case of limited specimen dimensions and test configurations which are prone to splitting. Beneficial characteristics of reinforcements, such as the high ductility and an additional load transfer by the reinforcement, can also be exploited in dowel connections in timber structures. For this purpose, future research should be directed towards an assessment of reinforced connections under consideration of practical issues related to the manufacturing and execution of connections.

In this context the influence of growth irregularities on such connections should also be investigated.

Acknowledgments Open access funding provided by [TU Wien (TUW)]. The authors gratefully acknowledge the financial support of the Austrian Research Promotion Agency and the wood industry partnership Building with Wood within CEI-Bois for funding the research work within project MechWood 2. This work forms part of that project. The MechWood 2 research partners are thanked for their cooperation and collaboration in this project. 
Open Access This article is distributed under the terms of the Creative Commons Attribution 4.0 International License (http:// creativecommons.org/licenses/by/4.0/), which permits unrestricted use, distribution, and reproduction in any medium, provided you give appropriate credit to the original author(s) and the source, provide a link to the Creative Commons license, and indicate if changes were made.

\section{References}

ASTM D5764-97a (2013) Standard test method for evaluating Dowel-Bearing strength of wood and wood-based products, American Society for Testing and Materials (ASTM). West Conshohocken, PA, USA

Bejtka I (2005) Verstärkung von Bauteilen aus Holz mit Vollgewindeschrauben (Reinforcement of structural timber components with fully threaded screws). Karlsruher Berichte zum Ingenieurholzbau, Band 2, Universitätsverlag Karlsruhe, Germany

Blass HJ, Schmid M, Litze H, Wagner B (2000) Nail plate reinforced joints with dowel-type fasteners. Proceedings of the World Conference on Timber Engineering 2000, Whistler, British Columbia, Canada. Proceedings pp 8641-8646

Blass HJ, Werner H (1988) Stabdübelverbindungen mit verstärkten Anschlussbereichen (Dowel-type connections with reinforced connection areas). Bauen mit Holz 90:601-607

Brühl F, Kuhlmann U, Jorissen A (2011) Consideration of plasticity within the design of timber structures due to connection ductility. Eng Struct 33:3007-3017

DIN EN 1995-1-1/NA (2013) Nationaler Anhang - National festgelegte Parameter - Eurocode 5: Bemessung und Konstruktion von Holzbauten - Teil 1-1: Allgemeines - Allgemeine Regeln und Regeln für den Hochbau (National Annex - Nationally determined parameters - Eurocode 5: Design of timber structures - Part 1-1: General - Common rules and rules for buildings). Deutsches Institut für Normung (DIN), Berlin, Germany

Ehlbeck J, Werner H (1992) Softwood and hardwood embedding strength for dowel-type fasteners. CIB-W18 Meeting 25, Paper 25-7-2, Ahus, Sweden

EN 1995-1-1 (2004) + AC (2006) + A1 (2008): Eurocode 5: Design of timber structures - Part 1-1: General - common rules and rules for buildings. European Committee for Standardization (CEN), Bruxelles, Belgium

EN 338 (2003) Structural timber - strength classes. European Committee for Standardization (CEN), Bruxelles, Belgium

EN 383 (2007) Timber structures - test method - determination of embedment strength and foundation values for dowel type fasteners. European Committee for Standardization (CEN), Bruxelles, Belgium

Franke S, Magnière N (2014) Discussion of testing and evaluation methods for the embedment behavior of connections. Proceedings of the International Network on Timber Engineering Research. INTER/47-7-1, Bath, United Kingdom

ISO 10984-2 (2009) Timber structures - dowel-type fasteners - Part 2: Determination of embedding strength. International Organization for Standardization (ISO), Geneva, Switzerland

Jorissen A, Fragiacomo M (2011) General notes on ductility in timber structures. Eng Struct 33:2987-2997

Larsen HJ, Jensen JL (2000) Influence of semi-rigidity of joints on the behaviour of timber structures. Prog Struct Eng Mater 2:267-277

Rodd PD, Leijten AJM (2003) High-performance dowel-type joints for timber structures. Prog Struct Eng Mater 5:7789

Sandhaas C, Ravenshorst GJP, Blass HJ, van de Kuilen JWG (2013) Embedment tests parallel-to-grain and ductility aspects using various wood species. Eur J Wood Wood Prod 71:599-608

Santos CL, de Jesus AM, Morais JJ, Lousada JL (2010) A comparison between the EN 383 and ASTM D5764 test methods for dowelbearing strength assessment of wood: experimental and numerical investigations. Strain 46:159174

Santos CL, de Jesus AM, Morais JJ, Fontoura BF (2013) An experimental comparison of strengthening solutions for doweltype wood connections. Constr Build Mater 46:114-127

Schoenmakers JCM, Svensson S (2011) Embedment tests perpendicular to the grain - optical measurements of deformation fields. Eur J Wood Wood Prod 69:133-142

Sjödin J, Serrano E, Enquist B (2008) An experimental and numerical study of the effect of friction in single dowel joints. Holz Roh Werkst 66:363-372

Whale LRJ, Smith I (1986) The derivation of design clauses for nailed and bolted joints in Eurocode 5. CIB-W18 Meeting 19, Paper 19-7-6, Florence, Italy 